\title{
Reflexões Sobre o Domínio do Pensamento Teórico na Organização dos Conteúdos Escolares com Base em Vasily Davydov
}

\author{
Eliana Cláudia Graciliano ${ }^{1}$ \\ Silvia Pereira Gonzaga de Moraes $^{2}$
}

\begin{abstract}
Resumo
Este texto parte do pressuposto de que a escola tem por especificidade 0 trabalho com conteúdos científicos. Assim, o objetivo deste artigo consiste em refletir sobre como os conteúdos escolares podem ser organizados pelos professores de modo que ocorra o domínio do pensamento teórico nos estudantes. A partir desse intento, as discussões apresentadas orientam-se pelos pressupostos da Teoria Histórico-Cultural, de modo especial no texto "0 que é a atividade de ensino-aprendizagem" de Davydov. Essa obra apresenta reflexões sobre a essência da aprendizagem escolar, que é o conhecimento teórico, e como ele pode ser usado em sala de aula. 0 estudo evidenciou que a verdadeira atividade de ensino-aprendizagem requer, além da linguagem, necessidades, motivos, metas, condições, meios, ações e operações, cujo fim desemboca em conscientização dos fenômenos estudados. As vias para o cumprimento desse objetivo podem ocorrer pela experimentação e a exploração, desde que sejam organizadas atividades voltadas para esse fim.
\end{abstract}

Palavras-chave: Teoria histórico-cultural. Atividade. Conhecimento científico.

${ }_{1}$ Graduada em Pedagogia. Pós-graduada em Psicopedagogia Institucional e mestre em Educação pela Universidade Estadual de Maringá (UEM). Doutoranda em Educação pela Universidade Federal de São Carlos. Atua como pesquisadora no Núcleo de Estudos e Pesquisas sobre a escola de Vigotsky - Neevy. Professora da Faculdade Educacional da Lapa (Fael). ecgraciliano@ hotmail.com

2 Docente da Universidade Estadual de Maringá (UEM). Doutora em Educação pela Universidade de São Paulo (2008). Mestre em Educação pela Universidade Federal de Santa Catarina (2000). Graduada em Ciências pela Fundação Faculdade de Filosofia, Ciências e Letras de Jandaia do Sul (1986), com complementação em Matemática pela Faculdade de Filosofia Ciências e Letras de Mandaguari (1987). Graduada em Pedagogia pela Fundação Faculdade de Filosofia Ciências e Letras de Jandaia do Sul (1991). Atua no ensino, extensão e pesquisa para a formação pedagógica de professores com ênfase na organização do ensino. Os subtemas de maior concentração são: Educação Matemática, Processo de Ensino e Aprendizagem, Formação de Professores e Prática de Ensino.silvia.moraes@uol.com.br 


\title{
REFLECTIONS ON THE DOMAIN OF THEORETICAL THINKING IN THE ORGANIZATION OF SCHOOL CONTENTS BASED ON VASILY DAVYDOV
}

\begin{abstract}
This text is based on the assumption that the school has the specificity of working with scientific content. Thus, the purpose of this article is to reflect on how school content can be organized by teachers so that the domain of theoretical thinking in students occurs. From this attempt, the discussions presented are guided by the assumptions of the Historical-Cultural Theory, especially in the text "What is Real Learning Activity?" of Davydov. This work presents reflections on the essence of school learning, which is theoretical knowledge, and how it can be used in the classroom. The bibliographical study evidenced that true teaching-learning activity requires, besides language, needs, motives, goals, conditions, means, actions and operations, whose end leads to awareness of the studied phenomena. The means of achieving this goal can be achieved through experimentation and exploitation, provided that activities are organized for this purpose.
\end{abstract}

Keywords: Historical-cultural theory. Activity. Scientific knowledge.

Recebido em: 10/4/2017

Aceito em: 7/8/2017 
Neste artigo discutimos como os conteúdos escolares podem ser organizados pelos professores de modo que ocorra a apropriação do conhecimento teórico/científico nos estudantes. Para tanto, nos orientamos pelos pressupostos da Teoria Histórico-Cultural, de modo especial no texto "O que é a verdadeira atividade de aprendizagem?", de Davydov (1999).

Esse texto apresenta reflexões pertinentes sobre a essência da aprendizagem escolar, que é o conhecimento teórico, e como esse tipo de conhecimento pode ser pensado e organizado pelos profissionais da educação. Em linhas gerais, a obra destaca a essência do trabalho do professor, a necessidade do conhecimento teórico como núcleo das ações a serem desenvolvidas na escola e como os experimentos didáticos podem elevar por superação o conhecimento empírico para o teórico.

Sabemos que a educação escolar, na sociedade contemporânea neoliberal, limita as possibilidades de pleno desenvolvimento humano. Tal ação justifica-se pelo modo de produção vigente, a qual necessita de indivíduos com perfil específico para manutenção e reprodução do sistema capitalista.

"O discurso é claro: é preciso, agora, elaborar uma nova pedagogia, um projeto educativo de outra natureza e assegurar o desenvolvimento de competências, valor agregado a um processo que, todavia, não é o mesmo para todos" (MORAES, 2003, p. 152). Ao atribuir à escola a formação de trabalhadores adaptáveis e com capacidades elogiáveis no mercado de trabalho, as ações dos sistemas educacionais nos governos neoliberais acabaram, intencionalmente, contribuindo para que os conteúdos escolares ficassem no plano superficial, sem que houvesse uma organização metodológica que elevasse o conhecimento empírico para o teórico. Este conhecimento não é considerado o objetivo da escola por tendências que visam à formação para adaptação dos sujeitos às necessidades do capital. Entendemos a especificidade do trabalho da escola com base em uma visão não de formação para adaptação, mas de desenvolvimento integral do homem.

Acreditamos que um indivíduo consciente de suas ações consiga, por meio da sua educação escolar e do trabalho, instrumentos efetivos para sua não alienação, chegando ao tão esperado desenvolvimento pleno. 
No intuito de conseguirmos contribuir com essa luta, urge, todavia, estudos no campo da didática e das metodologias para que o significado (o que se dá no contexto social) e o sentido (o pessoal) do conhecimento escolar para o estudante sejam convergentes na atividade de ensino.

Com base nas contribuições de Davydov, em sua publicação de 1999, "O que é a verdadeira atividade de aprendizagem?", apresentamos, neste texto, reflexões sobre a essência da aprendizagem escolar, que é o conhecimento teórico. Este somente pode ser desenvolvido, como afirmou o autor e como bem-argumentamos, mediante uma adequada organização dos conteúdos escolares. Somente esse tipo de conhecimento instrumentaliza os sujeitos a transformarem a realidade posta pela classe dominante e, por tal magnitude, torna-se pertinente reflexões com esta temática.

\section{O Que é a Atividade de Ensino-Aprendizagem para Davydov}

Davydov foi membro da Academia de Ciências Pedagógicas, doutor em psicologia e professor universitário. As premissas adotadas na Teoria Histórico-Cultural foram aprofundadas também por esse expoente. Seus estudos comprovaram que a aprendizagem e a educação formal determinam processos de desenvolvimento psíquico.

Apresentaremos, a seguir, as discussões realizadas sobre o texto "O que é a verdadeira atividade de aprendizagem?", de Davydov (1999), que estão organizadas em sete partes. A primeira delas apresenta o conceito de atividade; depois é feita a caracterização geral do que seria uma atividade de aprendizagem; na terceira parte o autor aborda as características do conhecimento teórico como conteúdo da atividade de aprendizagem, chegando à organização disso por meio de experimentos orientados aos alunos. Na quinta parte ele aponta princípios para se pensar ações básicas de aprendizagem, pontuando, em seguida, qual a base para o pensamento teórico; finaliza as discussões pleiteando a elaboração de um novo currículo baseado na atividade de aprendizagem. 
Embora seja um currículo pensado no contexto da União Soviética, os estudos de Davydov (1999) partem da argumentação de que a atividade de aprendizagem está imbricada à formação da consciência humana, indicando, para nós, uma sustentação geral do princípio do trabalho educativo.

Organizamos o estudo deste tópico na mesma sequência que o autor. Em seguida, tecemos reflexões relacionando a organização dos conteúdos escolares e o domínio do pensamento teórico nas instituições educativas, local do ensino por excelência.

\section{Conteúdo do Conceito de Atividade}

Atividade, para Davydov (1999, p. 1), “[...] é compreendida como o processo no qual a realidade é transformada pelos esforços criativos dos homens. O trabalho é a forma original desta transformação". Os componentes dessa atividade "são necessidades, motivos, metas, condições, meios, ações e operações”, explica Davydov (1999, p. 2).

Para ele, esses componentes carregam conteúdos "orientados-ao-objeto" e à própria atividade dirige-se à criação de algum produto final, quer seja material ou espiritual. Quando ele remete ao plano material, está reportando-se a produtos concretos, por exemplo máquinas, edifícios e objetos que cristalizaram os componentes da atividade. Já o plano espiritual/subjetivo seriam planos mentais, que podem ser partituras, fórmulas matemáticas, entre outras sistematizações. Se os componentes da atividade não resultarem em um produto final, não é considerada atividade.

\section{Uma caracterização geral da atividade de aprendizagem}

Davydov (1999) explica, primeiramente, que os componentes supralistados são conceitos gerais da atividade. Para ele, toda atividade tem um conteúdo específico, sejam jogos ou trabalhos. Por exemplo, a criança aprende quando brinca, quando pula amarelinha, mas sua finalidade não é aprender; o centro da atividade lúdica é o prazer, a imitação, etc. Na atividade do trabalho também há 
aprendizagem, mas não tem o prazer como centro. $\mathrm{O}$ trabalho visa a produzir algo. Na atividade de aprendizagem o produto é o novo pensamento do sujeito; trata-se de um produto mental, pois “"...] a aprendizagem escolar adequadamente organizada é o centro da atividade de aprendizagem” (DAVYDOV, 1999, p. 2); por isso, somente a atividade de aprendizagem escolar é a atividade cujo fim é a própria atividade, isto é, o centro da atividade escolar.

Assim,

[...] as crianças podem apropriar-se de conhecimentos e habilidades somente por meio da atividade de aprendizagem quando elas tiverem uma necessidade interna e motivação para fazê-lo. A atividade de aprendizagem envolve a transformação do material a ser apropriado e implica que algum produto mental novo, isto é, o conhecimento, seja adquirido. Necessidades de aprendizagem e motivos orientam as crianças para a apropriação de conhecimento como um resultado de transformações de um material dado (DAVYDOV, 1999, p. 2).

Para o autor, as necessidades da criança consistem em esforços para conhecer os aspectos gerais de um objeto. Com essa afirmação, acredita-se que o conhecimento teórico ocorre por meio da experimentação e da exploração. Segundo ele,

Temos que enfatizar que atividade de aprendizagem e objetivos de aprendizagem, respectivamente, estão conectados, antes de tudo, dentro do processo de transformação do material no qual a pessoa que aprende pode estudar, detectar e fixar alguns dos componentes centrais que destacam muitos traços externos de um material (DAVYDOV, 1999, p. 3).

Essa transformação do material e a fixação de componentes centrais sinalizam que experimentos ou ensaios sobre determinado fenômeno ou exploração pode ser um possível caminho para se inter-relacionar o conteúdo interno ao externo. Sigamos com esse entendimento.

Características do conhecimento teórico como conteúdo da atividade de aprendizagem 
Para Davydov (1999, p. 3), conhecimento teórico é aquilo que "representa as inter-relações entre o interno e externo, entre essência e aparência, entre o original e derivado", ou seja, o conhecimento que se apresenta em sua totalidade quer no externo, manifestado em ações/materiais, quer no interno, representado pelos planos mentais, é que evidencia a apropriação do pensamento teórico nos estudantes.

Em outras palavras, pode-se afirmar que o sujeito se apropriou do conhecimento teórico se ele reproduziu o processo de sua origem; reprodução essa que tem um propósito orientado-para-a-aprendizagem, que requer mobilização do intelecto e das ações advindas desse intelecto.

Davydov (1999, p. 3) ressalta que os "experimentos orientados para a aprendizagem são o único caminho para as crianças identificarem as inter-relações que existem entre o conteúdo interno e externo do material a ser apropriado". Isso ocorre porque a atividade de aprendizagem precisa de uma necessidade a ser criada e uma habilidade para executá-la. Quando o sujeito aprende, ele reproduz de forma consciente suas ações.

\section{A organização da atividade de aprendizagem dos alunos}

A partir do entendimento de que experimentos orientados possibilitam a inter-relação de conteúdos externos e internos, o autor disserta sobre a organização adequada para a atividade de aprendizagem.

Para Davydov (1999, p .4), “organização 'verdadeira' da atividade de ensino-aprendizagem começa gradualmente, mas persistentemente, inculcando tais necessidades na criança". Segundo ele, a criação de necessidade para a atividade de aprendizagem conta com duas principais condições: a primeira é entender a criação de necessidade fora de um contexto forçoso, e a segunda é a proposta de tarefas de aprendizagem em que haja a experimentação do material a ser apropriado. 
Conforme o autor, a tarefa de aprendizagem "requer que os alunos analisem as condições em que se originaram conceitos científicos do conhecimento teórico, e que eles se apropriem de modos generalizados de agir" (DAVYDOV, 1999, p. 4). Ou seja, a apropriação conceitual é o mesmo que o desenvolvimento de um modo de ação.

Diante dessa concepção, as tarefas de aprendizagem não se limitam à exposição de algo ou a recontar algum texto, mas, sim, em atividades nas quais as crianças tenham de recorrer a experimentos mentais para se apropriarem do conceito que é o objeto do ensino. Ou seja, "para formular e resolver tarefas de aprendizagem é necessário utilizar um material em que as crianças possam realizar as respectivas transformações e fazer experimentos mentais ou materiais objetais com este material”, explica Davydov (1999, p. 5).

Ante o exposto, evidencia-se no autor a preocupação em pensar em uma organização adequada da atividade de aprendizagem pelo professor. Para ele, boas oportunidades de aprendizagem podem ocorrer se forem formuladas para as crianças tarefas de aprendizagem que as mobilizem para superação de determinados desafios. Para tanto, o autor propõe ações de aprendizagem que, segundo ele, levam a uma organização adequada da atividade de aprendizagem.

\section{Ações básicas de aprendizagem}

Davydov (1999) apresenta cinco ações de aprendizagem. A primeira delas conta com a resolução de uma tarefa diferente da já ensinada. Com isso, as crianças pequenas precisam "pesquisar e caracterizar os traços básicos do mesmo tipo de tarefa", explica Davydov (p. 5).

Para clarear esta primeira ação, recorreremos a um exemplo de tarefa de aprendizagem dada pelo autor na área matemática sobre o conceito de multiplicação: a tarefa consiste na medição de um objeto muito grande usando um instrumento de medida pequeno e, junto a isso, os estudantes devem pensar em um tempo rápido de resolução e em um resultado preciso. 
Essa tarefa a ser resolvida conta com a resolução de um problema por vias diferentes das ensinadas. Pensar a multiplicação como resposta para uma ação prática implica descobrir a necessidade de usar a ação matemática nas relações de medida empregadas em nosso cotidiano.

A segunda ação apontada por Davydov (1999) é a criação de modelos que representem as relações já conhecidas do material. Esses modelos podem ser em forma de objeto, símbolo ou gráfico, que, no exemplo anterior, seria o algoritmo, que simboliza a quantidade de vezes que o instrumento de medida pequeno equivale ao objeto medido.

A terceira ação consiste "na definição concreta do sistema de relações encontradas nas várias tarefas específicas que estão uniformes com a tarefa de aprendizagem" (DAVYDOV, 1999, p. 5). Em outras palavras, seria a relação que se estabelece na resolução de um problema a outros da mesma proporção. Ou seja, a forma como podemos pensar para resolver a tarefa da medição de algo grande usando um instrumento de medida pequeno, por exemplo, permite a percepção do uso da multiplicação em outras situações que requeiram o uso e a comparação de instrumentos de medida.

A quarta ação de aprendizagem é o controle que permite às crianças corrigir sua execução; a quinta e última ação é a avaliação sobre o que foi apropriado pelo aluno pelas relações que estabeleceu com a tarefa de aprendizagem.

Em linhas gerais,

[...] a organização adequada da atividade de aprendizagem exige que o professor, contando com a necessidade e a prontidão das crianças em apropriar-se do conhecimento teórico, seria capaz de formular, baseando-se na matéria específica dentro de uma determinada área, uma tarefa de aprendizagem que possa ser resolvida por meio das ações discutidas anteriormente (ou seja, o professor deveria usar os meios definidos para promover a necessidade existente da criança e a capacidade de receber uma tarefa de aprendizagem e executar ações de aprendizagem). Neste caso, o professor instrui (ensina) as matérias respectivas de acordo com os requisitos da atividade de aprendizagem (ou seja, por meio da resolução pelos alunos de tarefas de aprendizagem) (DAVYDOV, 1999, p. 6). 
Observa-se que o autor dá especial destaque ao trabalho do professor, bem como à necessidade de esse profissional ter o conhecimento teórico como núcleo de suas ações. Ao afirmar que os experimentos didáticos iniciam com a criação de necessidades com observações das condições e tarefas de aprendizagem, ele sinaliza que este é o profissional que assume por excelência o processo de aprendizado do pensamento teórico do outro. A seguir evidencia-se essa observação.

Atividade de aprendizagem como base para o desenvolvimento do pensamento teórico

Davydov (1999) acredita que a consciência e o pensamento teórico são formados e desenvolvidos via "ação-desempenho-visual", "imagem-visual" e o que ele chama de "discursivo-verbal". Tais formas de aquisição desse pensamento encontram-se na realidade das crianças, seja nas artes, ciências, nas práticas morais ou nas leis. Isso evidencia que esse pensamento não representa uma atitude abstrata, mas, sim, resolução de tarefas cotidianas. Para Davydov (1999, p. 6),

[...] apenas o pensamento e a consciência dialética podem resolver esses conflitos. Por isso, o termo pensamento teórico é ao mesmo tempo um pensamento dialético. A consciência teórica direciona a atenção de humanos para a necessidade de entender suas próprias ações cognitivas, para considerar o próprio conhecimento. Em termos filosóficos isso se refere à reflexão.

Diante desse entendimento, quando há o pensamento dialético e a consciência desenvolvendo e funcionando, existe a "atividade de aprendizagem". Por isso, nessa atividade o pensamento empírico racional não basta, posto que são necessárias ações mentais dirigidas para "educar e desenvolver a capacidade de todos os estudantes para o pensamento dialético em todas as matérias" (DAVYDOV, 1999, p. 7). Com isto,

[...] partindo do entendimento de que o pensamento empírico racional não basta como base para o pensamento teórico e, que é preciso, uma solução dialética das tarefas para então adquirirmos o pensamento teórico, temos que a influência desenvolvimental da atividade de aprendizagem será aumentada consideravelmente se combinada com a atividade laboral e o trabalho produtivo das crianças que estão relacionados às origens das transformações e experimentos genuínos, criativos, com objetos. Combinações dos 
experimentos de aprendizagem com as atividades laborais fornecem novas fontes para o desenvolvimento do potencial criativo das crianças, ou seja, sua personalidade (DAVYDOV, 1999, p. 8).

Acreditar que a escola é o local que tem a especificidade de trabalhar com o pensamento teórico em detrimento do empírico, dá a ela o desafio de organizar o ensino, de modo que os estudantes se apropriem dessa forma de pensar como condição de transformação da realidade posta pela classe dominante. Para tanto, o autor sugere a elaboração de um novo tipo de currículo escolar explicitado na sequência.

\section{Elaboração de um novo currículo baseado na atividade de aprendizagem}

Davydov (1999) apresenta quatro sugestões para responder à questão central do seu texto "O que é a verdadeira atividade de aprendizagem?" Para ele, atividade de aprendizagem conta com um currículo que supera uma visão tradicional ancorada na lógica-formal dos conteúdos, sendo esse o primeiro ponto a ser repensado.

Esse tipo de organização categoriza ou conglomera conhecimentos do particular para o geral, cultivando um modo empírico de pensar as coisas do mundo e, segundo o autor, "a escolarização sistemática que segue programas tradicionais, de um lado forma na criança conceitos empíricos e noções sobre vários domínios da vida real e, do outro, cultiva um modo empírico de pensar" (DAVYDOV, 1999, p. 8), fator que não justifica seu uso nas escolas.

Ir além do pensamento empírico, que é sua segunda sugestão, desemboca em um terceiro ponto, que é o de partir da análise do geral para o específico, pois

[...] os aspectos particulares dos materiais são derivados do "conhecimento geral". O pensamento dos alunos se move do geral para o particular dentro de um material. Os currículos que fornecem tais direções de pensamento ajudam a estabelecer relações com sistemas integrados de conhecimento. $\mathrm{O}$ papel principal na apropriação de tal conhecimento pertence às ações dos alunos (DAVYDOV, 1999, p. 9). 
Para o autor, o tipo de ensino que tem um efeito desenvolvimental não se origina no cotidiano das pessoas. Esse fato não exclui a importância dele, apenas não o considera como aquele que mobiliza os conceitos dialéticos do pensamento, sendo este a última sugestão para elaboração de um novo tipo de currículo. Davydov (1999, p. 10) assevera que "o pensamento teórico ajuda os alunos a se orientarem entre as relações gerais e permite-lhes derivar dessas relações várias consequências específicas".

Com isso, (a) romper à lógica-formal do currículo, (b) sair do pensamento empírico (senso comum), (c) partir do geral para o específico e (d) acreditar que o pensamento teórico é assimilado na escola, são os princípios gerais para um currículo baseado na atividade de aprendizagem.

\section{A Organização dos Conteúdos Escolares e o Domínio do Pensamento Teórico: Primeiras Aproximações}

Vimos até agora que a atividade à qual Davydov (1999) se reporta assume por conceito geral a criação de necessidades, motivos, metas, condições, meios, ações e operações. Tais conceitos são orientados-ao-objeto, podendo manifestar-se no plano material, palpável, ou no plano espiritual/subjetivo, idealizado.

Leontiev (2005, p. 64) nos auxilia no entendimento deste conceito ao afirmar que

qualquer objeto criado pelo homem - desde o mais simples utensílio à moderníssima máquina calculadora eletrônica - realiza tanto a experiência histórica do gênero humano como as capacidades intelectuais formadas nesta experiência. [...] no desenvolvimento do cérebro, as conquistas do desenvolvimento histórico do homem consolidam-se em objetos materiais e em fenômenos ideais (linguagem, ciência) criados pelo homem.

Esse produto criado pelo homem, e que encarna um processo mental, é apropriado por outras pessoas pela interação social; um ato mediado que tem a intencionalidade de explicar formas, meios e fins para domínio desse produto 
ao outro. O sentido pessoal e o significado dado socialmente coincidem em uma atividade predeterminada para isso. No caso da escola, manifestam-se pelos conteúdos escolares.

O caminho apontado para a atividade de aprendizagem, defendido por Davydov (1999), segue pelo plano de experimentos orientados, que contam com a exploração e a experimentação para inter-relacionar fatores externos e internos, como já explicado.

Para nós, essa defesa reafirma nosso posicionamento de que

a criança não nasce com órgãos preparados para cumprir funções que representam o produto do desenvolvimento histórico do homem; estes órgãos desenvolvem-se durante a vida da criança, derivam da sua apropriação da experiência histórica. Os órgãos destas funções são os sistemas funcionais cerebrais ("órgãos fisiologicamente móveis do cérebro", segundo Ujtomsky), formados com o processo efetivo de apropriação (LEONTIEV, 2005, p. 72).

Tal processo efetivo, para nós, justifica a função da escola atribuída pela Teoria Histórico-Cultural, pois acreditamos que compete a essa instituição o trabalho intencional para apropriação de conteúdos científicos, verdadeiros, e que são capazes de mobilizar ações mentais que gerem consciência das ações realizadas.

O tipo de conhecimento revelado pelos conteúdos escolares é que possibilitará à escola o processo efetivo de apropriação, como pontuou Leontiev (2005). Questionado sobre para que servem as escolas, Young (2007, p. 1.294) concluiu "que elas capacitam ou podem capacitar jovens a adquirir o conhecimento que, para a maioria deles, não pode ser adquirido em casa ou em sua comunidade, e para adultos, em seus locais de trabalho".

Então nos questionamos: E que conhecimento seria esse?

Young (2007) explica que essa definição depende do que ele chama de propósito da escola e, nós, de posicionamento político. Vejamos: para ele, existem dois tipos - um conhecimento que depende do contexto do aluno e outro que independe. Coadunamos com Young (2007) ao assumir a defesa de uma 
formação contrária à lógica Neoliberal e, nesta ótica, o conhecimento esperado da escola é o que independe do contexto, sendo este o que ele classifica como "conhecimento poderoso":

Um é o conhecimento dependente do contexto, que se desenvolve ao se resolver problemas específicos no cotidiano. Ele pode ser prático, como saber reparar um defeito mecânico ou elétrico, ou encontrar um caminho num mapa. Pode ser também procedimental, como um manual ou conjunto de regras de saúde e segurança. O conhecimento dependente de contexto diz a um indivíduo como fazer coisas específicas. Ele não explica ou generaliza; ele lida com detalhes. O segundo tipo de conhecimento é o conhecimento independente de contexto ou conhecimento teórico. É desenvolvido para fornecer generalizações e busca a universalidade. Ele fornece uma base para se fazer julgamentos e é geralmente, mas não unicamente, relacionado às ciências. É esse conhecimento independente de contexto que é, pelo menos potencialmente, adquirido na escola e é a ele que me refiro como conhecimento poderoso (YOUNG, 2007, p. 1.296).

Com isso, resolver tarefas por caminhos não antes testados, criar modelos e definições, saber controlar e avaliar, são ações básicas de aprendizagem elencadas por Davydov (1999) o que também defendemos. Sforni (2015) complementa a discussão afirmando que para conseguir a formação do pensamento teórico, a escola precisa assentar-se em procedimentos didáticos voltados para a apropriação de conceitos como atividade mental.

Para Leontiev (2005), a aprendizagem mais importante para o desenvolvimento mental é a linguagem, pois

[...] o conteúdo da experiência histórica do homem, a experiência histórico-cultural, não está consolidada somente nas coisas materiais; está generalizada e reflete-se de forma verbal na linguagem. E precisamente nesta forma a criança acumula o conhecimento humano, os conceitos sobre o mundo que a rodeia $(2005$, p. 73$)$.

Para esclarecer o uso da linguagem como condição da promoção dos processos psíquicos, Leontiev (2005) traz um exemplo do ensino na aritmética que nos ajudará na melhor compreensão. Para ele, 
[...] o ensino na aritmética não deve começar, portanto, com a generalização, mas com a formação ativa na criança de ações com objetos externos e, paralelamente, com o movimento e o inventário destes. Posteriormente, estas ações externas transformam-se em linguagem (contar em voz alta), abreviam-se e adquirem por fim o caráter das ações internas (contar mentalmente), que se automatizam na forma de simples atos associativos (2005, p. 73).

Aos poucos, os fatores intrapsíquicos (externo) ajudam os sujeitos na organização do interpsíquico (interno), desde que sejam mobilizadas ações mentais favoráveis a isso. Isso quer dizer que "o desenvolvimento humano é decorrente das possibilidades criadas nas atividades humanas em geral", afirma Rigon et al. (2010, p. 51).

Conforme Leontiev (2005), a primeira etapa do processo geral de formação das operações de pensamento inicia-se quando um adulto mostra à criança o que quer que ela faça e qual o resultado esperado dessa ação. Quando a criança passa a realizar a atividade, de maneira geral podemos afirmar que ela adquiriu a base de orientação, como nomeia Leontiev (2005). A segunda etapa evidencia-se quando a criança verbaliza suas ações. Trata-se de palavras para organizar conceitos, pois a "criança começa a contar em voz alta, prescindindo dos objetos externos", explica Leontiev (2005, p. 74). A terceira etapa manifesta-se quando a ação é transferida para o plano mental, isto é, quando a criança deixa de contar em voz alta para fazê-la mentalmente, conforme conseguimos observar no exemplo da aritmética dado pelo autor.

Para Sforni (2015, p. 390), “a linguagem (do professor, dos alunos, dos textos científicos) é mediadora entre os dois planos: material e mental é condição para a abstração do conteúdo, para a passagem da ação externa, do plano material, para o pensamento teórico". Pode-se depreender que a linguagem é, então, fundamental para abstração do objeto de aprendizagem pelos estudantes, pois a palavra representa objetos e fenômenos do mundo em categorias gerais. Essa categoria que estamos falando é a generalização, ou seja, um conceito que revela um ato do pensamento e da linguagem. 
Com isso,

o conceito, portanto, se interpõe entre o sujeito e o objeto, favorecendo novas formas de pensamento e ação. O elemento novo que o domínio de conceitos possibilita ao sujeito não é a posse de maior quantidade de conteúdos, mas essencialmente uma nova qualidade de pensamento. A atenção, a percepção, a memória, a imaginação e o raciocínio do homem sobre o mundo objetivo são modificados pelas abstrações e generalizações conceituais (SFORNI, 2015, p. 5)

Diante desses motivos, acreditamos que o pensamento teórico se vincula ao desenvolvimento das funções psicológicas, porém num plano superior de formação.

Ou seja, a atenção, a percepção, a memória, o raciocínio, a imaginação, o sentimento desenvolvem-se à medida que são ativados. Tais atividades, no entanto, não se reduzem a exercícios para o desenvolvimento dessas funções: devem ser realizadas com os conteúdos curriculares, colocando de maneira integrada essas funções em movimento (SFORNI, 2015, p. 384).

Sabemos que a atividade mental é algo subjetivo à percepção das pessoas. Algumas manifestações, todavia, permitem perceber se os alunos estão em atividade mental com os conteúdos pelas manifestações externas reveladas, quer por gesto, fala ou expressões variadas. Por isso,

a partir do momento em que o uso dos signos é apropriado pelas ações práticas, ocorre uma reorganização destas de forma inteiramente nova. Assim, a criança passa a controlar o ambiente com a ajuda da fala, fato que promove alterações no próprio comportamento dela (RIGON et al., 2010, p. 61).

Tal relevância à linguagem evidencia que ela ocupa o eixo das relações entre a atividade de ensino-aprendizagem, cujo fim esperado é a "compreensão do concreto pela mediação do abstrato" (SFORNI, 2015, p. 392). O mesmo significa afirmar que a apropriação do conceito científico é como instrumento de interação com a realidade imediata ocorrida pela linguagem. 
Quando utilizamos os signos ou instrumentos simbólicos, passamos a representar mentalmente nosso ideal pelo mundo real, e "essa internalização permite ao homem operar mentalmente sobre o mundo sem se prender ao tempo, ao espaço e aos objetos concretos" (SFORNI, 2015, p. 2).

Destarte, o professor orienta o aluno das ações externas, palpáveis, às ações mentais, abstratas, permitindo e possibilitando vias de acesso aos conceitos essenciais a serem apreendidos. Sforni (2015, p. 11) explica que "o afastamento da experiência sensorial permite o reconhecimento desses elementos em outros objetos ou fenômenos, ou seja, por meio da abstração, que parte de uma ação externa dirigida e consciente, torna-se possível a generalização".

Queremos afirmar que a verdadeira atividade de ensino - aprendizagem defendida por Davydov (1999) - requer a mobilização de ações e operações mentais, cujo fim desemboca em conscientização dos fenômenos estudados. As vias para o cumprimento desse objetivo podem ocorrer pela experimentação e a exploração, desde que sejam organizadas atividades voltadas para esse fim. Assim, os conteúdos escolares podem desenvolver o pensamento teórico desde que a atividade de ensino priorize ações em que os estudantes realizem o pensamento dialético.

Desse modo,

o currículo tem que levar em consideração o conhecimento local e cotidiano que os alunos trazem para a escola, mas esse conhecimento nunca poderá ser uma base para o currículo. A estrutura do conhecimento local é planejada para relacionar-se com o particular e não pode fornecer a base para quaisquer princípios generalizáveis. Fornecer acesso a tais princípios é uma das principais razões pelas quais todos os países têm escolas (YOUNG, 2007, p. 1.299).

Em linhas gerais, podemos afirmar que o desafio das escolas consiste em pensar como promover ações que gerem atividades de ensino e aprendizagem que justifiquem sua razão de existir sem que seja a perpetuação de mão de obra "qualificada" para promoção da classe burguesa. Acreditamos que "O processo educativo é central à formação do homem em sua especificidade histórica, pois 
permite que não seja necessário reinventar o mundo a cada nova geração, permite que se conheça o estágio de desenvolvimento humano atual para que se possa superá-lo" (RIGON; ASBAHR; MORETTI, 2010, p. 27).

Diante dessas reflexões, finalizamos ressaltando que nossos estudos caminham na defesa de uma instituição que ensine com excelência, em que os professores tenham o domínio teórico para libertarem opressores das mazelas do capital e que tenham em suas mãos condições efetivas de herdarem os bens historicamente elaborados. Os caminhos para isso podem ser vislumbrados a partir do texto "O que é a verdadeira atividade de aprendizagem?", de Davydov (1999), uma vez que essa obra apresentou reflexões sobre a essência da aprendizagem escolar, que é o conhecimento teórico, e como pode ser pensado em sala de aula, inclusive no que diz respeito aos princípios gerais para um currículo baseado na atividade de aprendizagem.

\section{Considerações Finais}

Compreendemos que o estudo de teorias que sinalizem o tipo de homem em seu tempo conduz a uma compreensão mais contextualizada e dinâmica dos processos de ensino e aprendizagem dos conceitos qualitativos sobre seu desenvolvimento psíquico.

Embora a Teoria Histórico-Cultural não tenha tido, em suas raízes, a intenção de embasar a prática pedagógica, acreditamos que estudá-la se faz pertinente devido aos princípios educativos vislumbrados nos escritos de autores russos, pois "os autores da Teoria Histórico-Cultural deixam pistas para pensarmos a organização de um ensino" (SFORNI, 2015, p. 379).

Para nós, as proposições dessa teoria oferecem aportes para se pensar no processo educativo que conduza ao processo de humanização, o qual se dá a partir da inserção do indivíduo, desde seus primeiros dias, em seu meio cultural, por intermédio da apropriação das objetivações produzidas historicamente, dependendo mais dessas do que propriamente de sua herança genética ou capacidades biológicas para se desenvolver. 
Tal conceituação do processo de desenvolvimento psíquico sinaliza que o processo educativo possibilita ao sujeito potencialização das ações mentais pela elevação do pensamento empírico para o teórico.

Pensar e operar com os fenômenos, por meio de instrumentos simbólicos, dão aos humanos justificativas que os afastam do progresso animal. Utilizar palavras como sistema de códigos que expressam o pensamento individual e coletivo aproximou o homem de sua espécie e o capacitou para aquisição dos bens historicamente produzidos.

A escola, dentro dessa concepção, eleva o potencial humano quando organiza atividades de ensino-aprendizagem que gerem o domínio do pensamento teórico, pois acredita-se que "[...] quando formamos nas crianças necessidade para a atividade de aprendizagem e a habilidade de executar tal atividade, estamos contribuindo consideravelmente para o seu desenvolvimento pessoal" (DAVYDOV, 1999, p. 2).

Este texto contemplou nossas primeiras aproximações sobre a organização dos conteúdos escolares defendidos por Davydov (1999). Deste, emergem estudos futuros para que possamos contribuir para se pensar o fenômeno educativo como propulsor do pleno desenvolvimento humano.

\section{Referências}

DAVYDOV, Vasily V. O que é a verdadeira atividade de aprendizagem? Tradução Cristina Pereira Furtado. Revisão da tradução José Carlos Libâneo e Raquel A. Marra da Madeira Freitas. 1999. (What is real learning activity).

LEONTIEV, A. N. Os princípios do desenvolvimento mental e o problema do atraso mental. In: LEONTIEV, A. V. et al. Psicologia e pedagogia: bases psicológicas da aprendizagem e desenvolvimento. São Paulo: Centauro, 2005. p. 87-105.

MORAES, M. C. M. Recuo da teoria. In: MORAES, Maria Célia M. de et al. Iluminismo às avessas: produção de conhecimento e políticas de formação docente. Rio de Janeiro: DP\&A, 2003.

RIGON, Algacir José; ASBAHR, Flavia da Silva Ferreira; MORETTI, Vanessa Dias. Sobre o processo de humanização. In: MOURA, Manoel Oriosvaldo (Org.). A atividade pedagógica na teoria histórico-cultural. Brasília: Líber, 2010. p. 13-44. 
RIGON, A. et al. O desenvolvimento psíquico e o processo educativo. In: MOURA, Manoel Oriosvaldo de (Org.). A atividade pedagógica na teoria histórico-cultural. 1. ed. Brasília, DF: Liber Livro Editora, 2010. p. 45-66.

SFORNI, M. S. F. Interação entre didática e teoria histórico-cultural. Educação e Realidade, Porto Alegre, v. 40, n. 2, abr./jun. 2015. Disponível em: <http://seer.ufrgs.br/index. php/educacaoerealidade/article/view/45965/33402>. Acesso em: 4 ago. 2001.

. Ensino, aprendizagem e desenvolvimento: contribuições da teoria da atividade. In: DE OLIVEIRA, Maria Cláudia Santos Lopes et al. (Org.). Desenvolvimento Humano: Cultura e Educação. 1 ed. Campinas: Editora Alínea, 2016, p. 53-66.

YOUNG, Michael. Para que servem as escolas? Educação e Sociedade, Campinas, vol. 28, n. 101, p. 1.287-1.302, set./dez. 2007. Disponível em: <http://www.scielo.br/pdf/es/ v28n101/a0228101.pdf>. Acesso em: 21 jun. 2017. 